\title{
Polidocanol foam sclerotherapy in the treatment of hemorrhoidal disease in patients with bleeding disorders: a multicenter, prospective, cohort study
}

\author{
P. Salgueiro ${ }^{1,2}$ - A. Rei $^{1} \cdot$ M. Garrido ${ }^{1} \cdot$ B. Rosa ${ }^{3} \cdot$ A. M. Oliveira ${ }^{4} \cdot$ T. Pereira-Guedes $^{1} \cdot$ S. Morais ${ }^{5} \cdot$ F. Castro-Poças $^{1,2}$
}

Received: 3 November 2021 / Accepted: 13 February 2022 / Published online: 25 February 2022

(c) Springer Nature Switzerland AG 2022

\begin{abstract}
Background The management of hemorrhoidal disease (HD) in patients with bleeding disorders (BD) is challenging. Polidocanol foam sclerotherapy (PFS) is associated with a low rate of bleeding complications. The aim of this study was to compare the efficacy and safety of PFS in the treatment of HD in patients with and without BD.

Methods This prospective, multicenter, cohort study enrolled patients with (group B) and without (group A) BD, with symptomatic internal HD grades I-III over an 18-month period. All patients were treated with PFS. Patients with congenital BD did not undergo prior replacement therapy and those with acquired BD due to antithrombotic drugs, did not discontinue therapy. Efficacy outcomes included therapeutic success and HD recurrence during a 1-year follow-up period. To evaluate safety the complications related to PFS were recorded.

Results We included 228 patients (group A: 155, group B: 73; male/female: 114/114; mean age: $59.4 \pm 15.9$ years). The baseline hemorrhoidal disease bleeding grade $(p<0.001)$ and Sodergren hemorrhoidal symptom severity score $(p=0.019)$ were higher for group B. The overall therapeutic success rate was $93.4 \%$ with an average number of sessions of $1.51 \pm 0.74$, significantly higher for group B $(1.68 \pm 0.86$ vs $1.43 \pm 0.65, p=0.013)$. Complications occurred in $11.4 \%$ of the patients, with bleeding reported in $4.8 \%$. The majority of complications were mild (96.2\%). No significant differences between the two groups were observed for therapeutic success, recurrence, or complication rate.

Conclusions Patients with BD may have more symptomatic HD at baseline. Even so, PSF showed similar effectiveness and safety in patients with BD compared to patients without BD.
\end{abstract}

Keywords Polidocanol foam $\cdot$ Hemorrhoidal disease $\cdot$ Sclerotherapy $\cdot$ Bleeding disorder

\section{Introduction}

Hemorrhoidal disease (HD) is one of the most common proctologic diseases [1-5]. The management of HD should be guided by patients' preference, comorbidities, disease grade, and treatment efficacy and safety [1, 6-14].

For symptomatic internal HD grades I to III refractory to conservative management, an office-based procedure should be offered as first line treatment $[1,7,15-17]$. Rubber band ligation (RBL) has been recommended as the gold standard treatment due to higher efficacy and lower recurrence rate $[1,11,15,18,19]$. However, high post-procedural bleeding rates (ranging from 3.5\% to-50\%), including late bleeding, have been reported $[1,15,18,20]$. Sclerotherapy is associated with lower bleeding rates but is more recurrence-prone $[1,15,21-24]$. The innovative use of polidocanol as a foam has drawn attention in recent years because of its improved 
sclerosing capacity, superior efficacy, the need for fewer office-based sessions and less complications, including bleeding and pain [15, 21-23, 25, 26]. Polidocanol foam sclerotherapy (PFS) induces a local inflammatory reaction that leads to local sclerosis of submucosal tissue, and promotes fixation of the hemorrhoidal tissue and obliteration of the vascular bed with tissue fibrosis [27, 28]. This technique has been shown to be reproducible, cost effective, and associated with great patient satisfaction [15, 21-23, 26, 28-30].

Hemorrhoidal bleeding is both a major symptom and a treatment complication $[1,4,5]$. Patients with congenital or acquired (induced by antithrombotic therapy) bleeding disorders (BD) are vulnerable groups, with higher risk of bleeding. In these patients, HD management is more challenging as RBL and surgery might be contraindicated or require withholding of antithrombotic therapy, increasing the risk of thrombosis $[1,11,31,32]$.

With the increase in general life expectancy and high prevalence of cardiovascular disease, there is a growing use of antiplatelet and anticoagulant therapy, [33-36] which is associated with gastrointestinal bleeding risk ranging from 1.5 to $4.5 \%$ [37-42]. Patients with congenital BD, including hemophilia A and von Willebrand disease (VWD), are also predisposed to spontaneous, traumatic, and interventionrelated bleeding. Gastrointestinal bleeding is at least two times more frequent and can account for half of all bleedingrelated acute care admissions in these patients [43-45].

The management of HD in patients with congenital and acquired BD is far from optimally defined. Considering their higher bleeding risk and increased rate of surgical complications, they should benefit from less invasive office-based procedures for HD. Recently, Fernandes et al. [21] reported a promising triad of high efficacy, high tolerability, and high safety of PSF in a significantly large population that included patients with BD $[15,21]$. More robust data on efficacy and safety of PFS treatment on these patients is required.

The aim of our study was to prospectively evaluate the efficacy and safety of PSF in the treatment of internal refractory HD grades I to III, comparing outcomes of patients with and without $\mathrm{BD}$.

\section{Materials and methods}

\section{Study design}

We conducted a prospective, multicentre, cohort study enrolling patients with symptomatic HD grades I to III referred to the Proctology outpatient clinics of three tertiary hospitals.

The study was approved by the ethics committees of the intervening institutions and was registered at ClinicalTrials. gov with the identifier NCT04188171.

\section{Participant selection}

\section{Inclusion criteria}

Adult patients with HD grades I to III refractory to conservative therapy for at least 4 weeks (topical ruscogenin and trimebutine and oral diosmin), referred to the proctology outpatient clinics of three tertiary hospitals (Centro Hospitalar Universitário do Porto, Porto; Hospital da Senhora da Oliveira, Guimarães; and Hospital Professor Doutor Fernando Fonseca, Amadora), submitted to PFS from August 1st, 2018 until February 1st, 2020.

All participants had lower gastrointestinal endoscopy prior to inclusion.

Participants were assigned to one of two groups: group A, without $\mathrm{BD}$ (normal hemostasis laboratory tests and absent hemorrhagic symptoms) or group B, with BD (congenital $\mathrm{BD}$ or acquired due to antithrombotic therapy).

\section{Exclusion criteria}

The following patients were excluded: patients with known allergy to polidocanol, liver cirrhosis, inflammatory bowel disease, immunosuppression, other concomitant symptomatic perianal disease, pregnant and lactating women, history of HD office-based or surgical treatment in the previous 6 months.

\section{Visits and outcomes}

In the first visit, demographic data, HD baseline severity and presence and type of BD were collected. HD baseline severity was assessed using the Goligher classification (ESM Table 1) [12], the hemorrhoidal disease bleeding grade (HDBG) (ESM Table 2) and the Sodergren hemorrhoid symptom severity (SHSS) scoring system (ESM Table 3) $[9,10]$. All patients received information about the enrollment and signed informed consent.

This cohort study included an intervention period (3 months) for evaluating efficacy and safety outcomes and a follow-up period (1 year) to assess for recurrence of disease.

\section{Efficacy evaluation: intervention period and follow-up}

The primary outcome for efficacy evaluation during the intervention period was therapeutic success, defined by an improvement in HDBG and SHSS score over baseline.

The required number of sessions (maximum of 3 , at 1-month intervals) was decided by clinical and anoscopic evaluation: if after a month from the last intervention the patient had no significant HD on anoscopy, a HDBG 
Table 1 Baseline characteristics and severity of hemorrhoidal disease of the participants (group A - without bleeding disorder; group B - with bleeding disorder)

\begin{tabular}{|c|c|c|c|c|}
\hline & All $(n=228)$ & Group A $(n=155)$ & Group B $(n=73)$ & $p$ \\
\hline Age (years): Mean \pm SD & $59.4 \pm 15.9$ & $54.3 \pm 15.0$ & $70.1 \pm 12.0$ & $<0.001$ \\
\hline Gender: $n(\%)$ & & & & 0.118 \\
\hline Female & $114(50.0)$ & $83(53.5)$ & $31(42.5)$ & \\
\hline Male & $114(50.0)$ & $72(46.5)$ & $42(57.5)$ & \\
\hline BMI: Mean \pm SD & $26.2 \pm 4.5$ & $26.0 \pm 4.5$ & $26.7 \pm 4.5$ & 0.312 \\
\hline Goligher grade: $\mathrm{n}(\%)$ & & & & 0.054 \\
\hline I & $45(19.7)$ & $36(23.2)$ & $9(12.3)$ & \\
\hline II or III & $183(80.3)$ & $119(76.8)$ & $64(87.7)$ & \\
\hline Hemorrhoidal disease bleeding grade: $n(\%)$ & & & & $<0.001$ \\
\hline 1 & $42(18.4)$ & $40(25.8)$ & $2(2.7)$ & \\
\hline 2 & $166(72.8)$ & $111(71.6)$ & $55(75.4)$ & \\
\hline 3 & $20(8.8)$ & $4(2.6)$ & $16(21.9)$ & \\
\hline $\begin{array}{l}\text { Sodergren hemorrhoidal symptom severity score: } \\
\text { median (IQR) }\end{array}$ & $7(4)$ & $7(4)$ & $10(3)$ & 0.019 \\
\hline
\end{tabular}

$S D$ standard deviation, $I Q R$ interquartile range

Tests used to compare variables between groups: $T$ test (Age and body mass index); Chi-square test (Gender, Goligher grade and initial bleeding grade); Mann-Whitney test (Sodergren score)

Table 2 Efficacy outcomes (intervention period)

\begin{tabular}{llllr}
\hline & All $(n=228)$ & $\begin{array}{l}\text { Group A } \\
(n=155)\end{array}$ & $\begin{array}{l}\text { Group B } \\
(n=73)\end{array}$ & $p$ \\
\hline $\begin{array}{l}\text { Therapeutic success— } n(\%) \\
\text { Yes }\end{array}$ & $213(93.4)$ & $144(92.9)$ & $69(94.5)$ & 0.646 \\
$\quad$ No & $15(6.6)$ & $11(7.1)$ & $4(5.5)$ & \\
Number of treatment sessions-Mean \pm SD & $1.51 \pm 0.74$ & $1.43 \pm 0.65$ & $1.68 \pm 0.86$ & \\
1 session— $n(\%)$ & $145(63.6)$ & $103(66.5)$ & $42(57.5)$ & 0.013 \\
2 sessions— $n(\%)$ & $50(21.9)$ & $38(24.5)$ & $12(16.4)$ & \\
3 sessions— $n(\%)$ & $33(14.5)$ & $14(9.0)$ & $19(26.0)$ & \\
Polidocanol dosage (total)—Mean \pm SD & $22.6 \pm 10.9$ & $22.5 \pm 10.5$ & $22.9 \pm 11.7$ & 0.763 \\
Bleeding grade variation*-Mean \pm SD & $-1.54 \pm 0.71$ & $-1.39 \pm 0.70$ & $-1.85 \pm 0.64$ & $<0.001$ \\
Sodergren score variation*-Mean \pm SD & $-7.31 \pm 3.70$ & $-7.14 \pm 3.70$ & $-7.67 \pm 3.70$ & $<0.001$ \\
\hline
\end{tabular}

SDstandard deviation

*Variable computed as measurement in the end of the intervention period minus baseline

Tests used to compare variables between groups: $T$ test (Average number of treatment sessions; Polidocanol dosage, Sodergren score variation); Mann-Whitney test (Bleeding grade variation, Goligher grade variation); Chi-square test (Therapeutic success)

\begin{tabular}{lllll}
\hline & All $(n=228)$ & Group A $(n=155)$ & Group B $(n=73)$ & $P$ \\
\hline $\begin{array}{l}\text { Global complications }- \\
n(\%)\end{array}$ & $26(11.4)$ & $19(12.3)$ & $7(9.6)$ & 0.554 \\
Mild & 25 & 19 & 6 & \\
Severe & 1 & 0 & 1 & \\
Bleeding $-n(\%)$ & $11(4.8)$ & $7(4.5)$ & $4(5.5)$ & 0.751 \\
Mild & 10 & 7 & 3 & \\
Severe & 1 & 0 & 1 & \\
\hline
\end{tabular}

Tests used to compare variables between groups: Chi-square test 
score $\leq 1$ and a SHSS $=0$, he would not be candidate to further therapy. Therapeutic failure was defined by maintenance or worsening of the initial HDBG and SHSS after 3 treatment sessions.

Number of office-based therapy sessions was defined as secondary efficacy outcome.

The efficacy outcome during the follow-up period was recurrence of disease (for those with therapeutic success), defined by a SHSS and HDBG score greater than at the end of the intervention period. Regardless of the number of treatment sessions, all participants were evaluated for recurrence at consecutive periods of 3 months for a 12-month period.

\section{Safety evaluation}

PFS-related complications were reported throughout the study. These were classified as mild if limited (e.g., pain/ discomfort, minor bleeding, external hemorrhoidal thrombosis not requiring intervention), or severe if implying additional intervention, clinical risk and/or long-term effect (e.g., bleeding requiring blood transfusion, with hemodynamic instability or need of urgent surgery; external thrombosis requiring surgical intervention; urinary retention, prostatic infection, or sexual dysfunction in men; perineal abscess or sepsis).

\section{Procedures and technical aspects}

Procedures were performed on an outpatient basis, without use of sedation or local anesthesia, by three experienced proctologists. The patients with congenital BD did not have prior replacement therapy and those with acquired BD did not suspend antithrombotic therapy. A cleaning enema was prescribed before each session.

Polidocanol foam was prepared according to the Tessari's technique, using $4 \mathrm{ml}$ of liquid polidocanol 3\% (Aethoxysklerol@) mixed with $16 \mathrm{ml}$ of air in two disposable $20 \mathrm{~mL}$ syringes, through a three-way tap [25, 46] (Fig. 1). The sclerosant was applied shortly after preparation to preserve stability, according to the Blanchard's technique (Fig. 2), through a disposable transparent anoscope, with the patient in genupectoral position, using an intravenous $20 \mathrm{G}$ needle adapted to a $10 \mathrm{~cm}$ reusable extender. The procedure has a fast learning curve, comparable to RBL. It could be performed on $>1$ hemorrhoidal pile (depending on the number of engorged hemorrhoidal cushions identified during anoscopy), with a maximum dose of $20 \mathrm{~mL}$ per session (each pile was injected until significant resistance was felt on the syringe plunger).

\section{Statistical analysis}

Differences in means were assessed with Student's $t$ test and differences in medians with the Kruskal-Wallis test. Comparison of categorical variables was assessed using

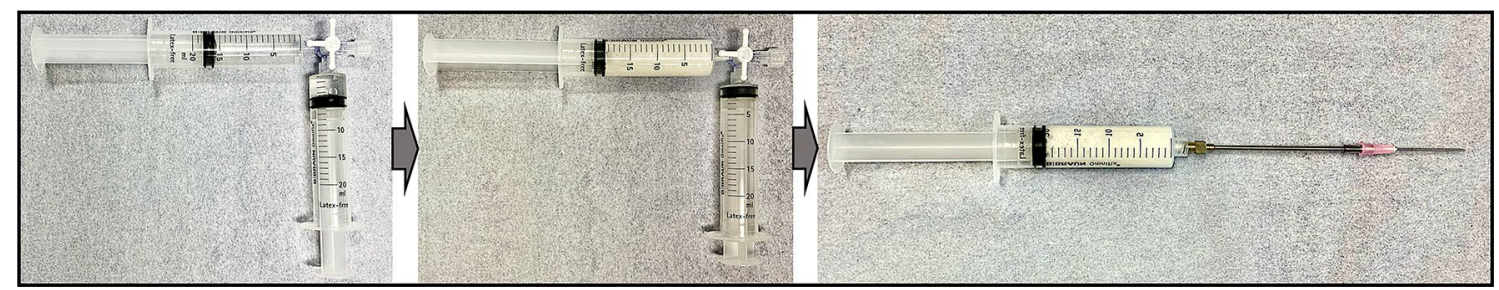

Fig. 1 Polidocanol foam preparation (Tessari’s technique)
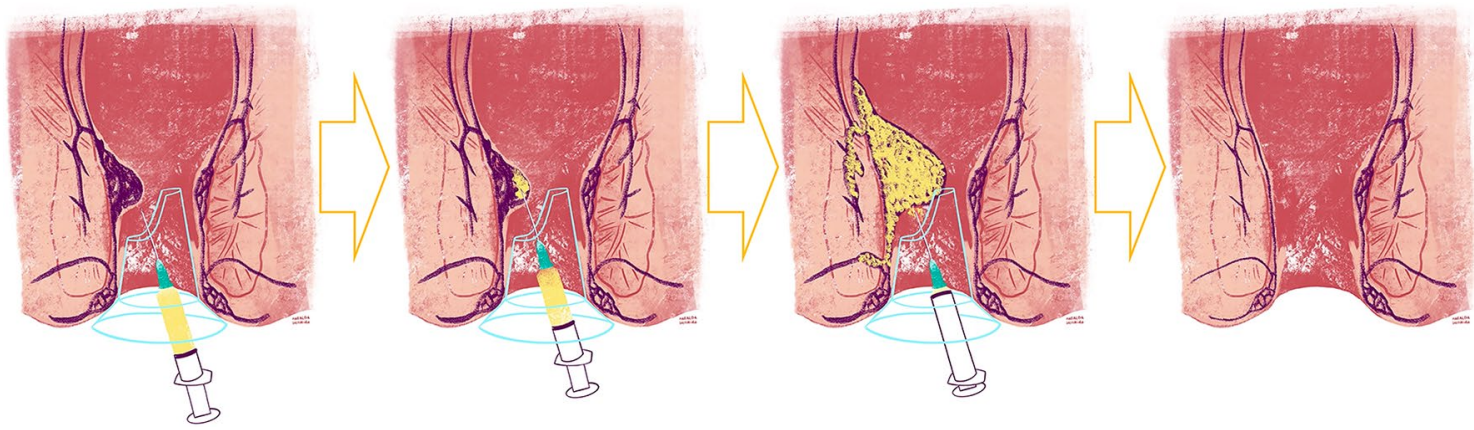

Fig. 2 Schematic representation of polidocanol foam sclerotherapy (according to Blanchard's technique) 
the Chi-square test or Fisher's exact test, where appropriate. Progression free-survival was compared using the Log Rank (Mantel-Cox) test. Cox regression was used to assess risk factors for recurrence and binary logistic regression to assess the risk factors for the occurrence of complications. The IBM® SPSS $®$ statistics software version 26.0 was used for all the statistical analysis. A $p$ value $<0.05$ was regarded as statistically significant.

\section{Results}

\section{Baseline characteristics}

From a total of 261 patients (24 patients did not meet inclusion criteria and 9 declined to participate), 228 were enrolled in the study (male/female: 114/114; mean age: $59.4 \pm 15.9$ years). One hundred and fifty-five patients were included in group A (without BD) and 73 patients in the group B (with BD) (Fig. 3). Group B was further divided into 7 subgroups according to type of BD (Fig. 4). Sixtyfour patients were on antithrombotic therapy (including an antiplatelet or anticoagulant drug or both) and 9 patients had hereditary BD including VWD $(n=3)$, severe hemophilia A $(n=2)$, inherited macrothrombocytopaenia $(n=1)$ and hyperfibrinolysis syndrome $(n=3)$, with bleeding score by ISTH-BAT (international society of thrombosis and hemostasis - bleeding assessment tool) consistent with moderate hemorrhagic disease. [47]

Considering the baseline characteristics of the participants (Table 1), the mean age was significantly higher for Group B $(70.1 \pm 12.0$ years vs $54.3 \pm 15.0$ years, $p<0.001)$. Regarding HD baseline severity, significantly more patients in the group B had HD with HDBG 2 or 3 (74.2\% vs $97.3 \%$, $p<0.001)$ and SHSS score was also significantly higher for this group (7 vs $10, p=0.019$ ).

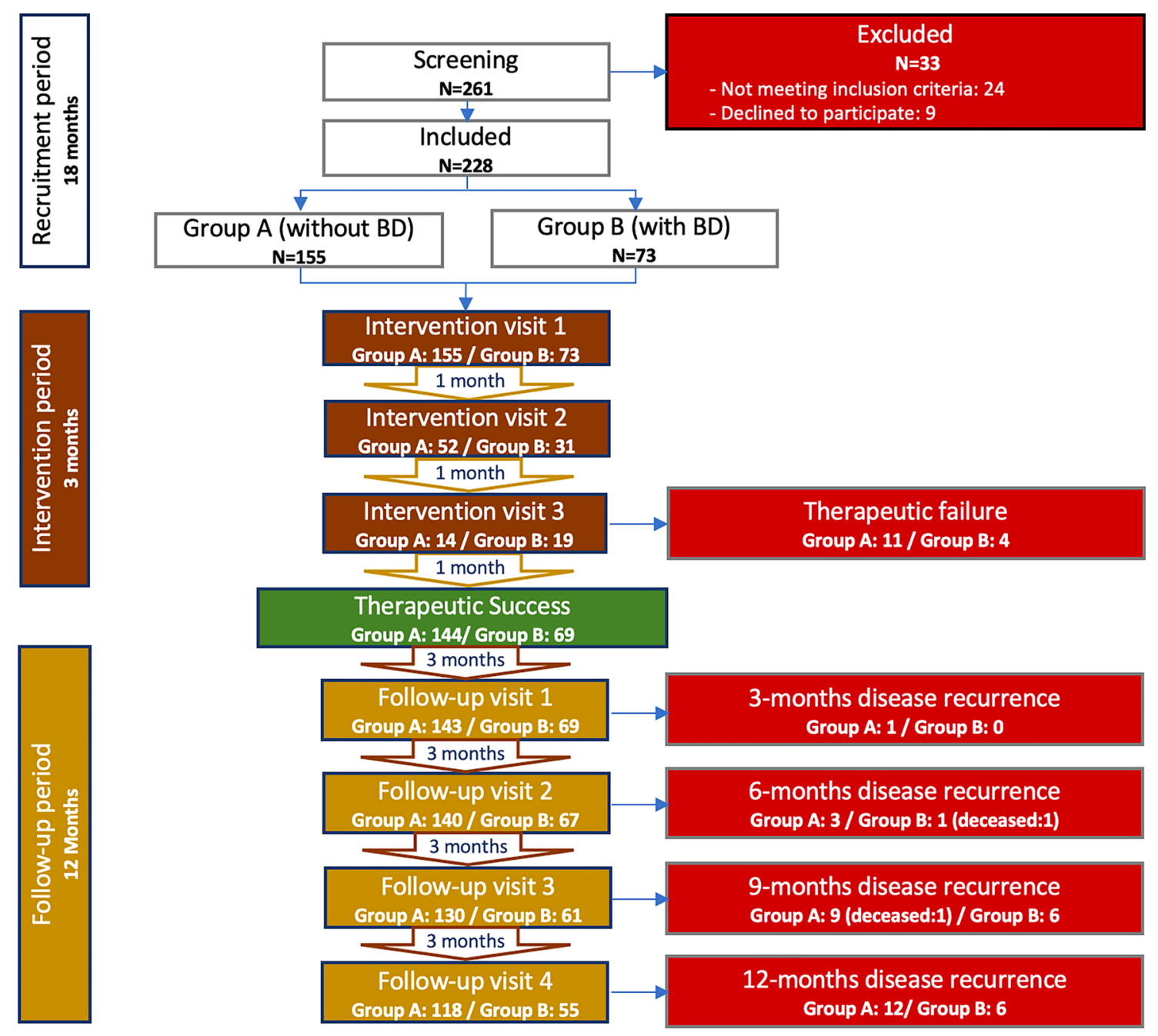

Fig. 3 Study flowchart. BD: bleeding disorders 
Fig. 4 Participants enrolled in the study (Group B subgroups). $A S A$ aminosalicylic acid, DOAC Direct oral anticoagulants

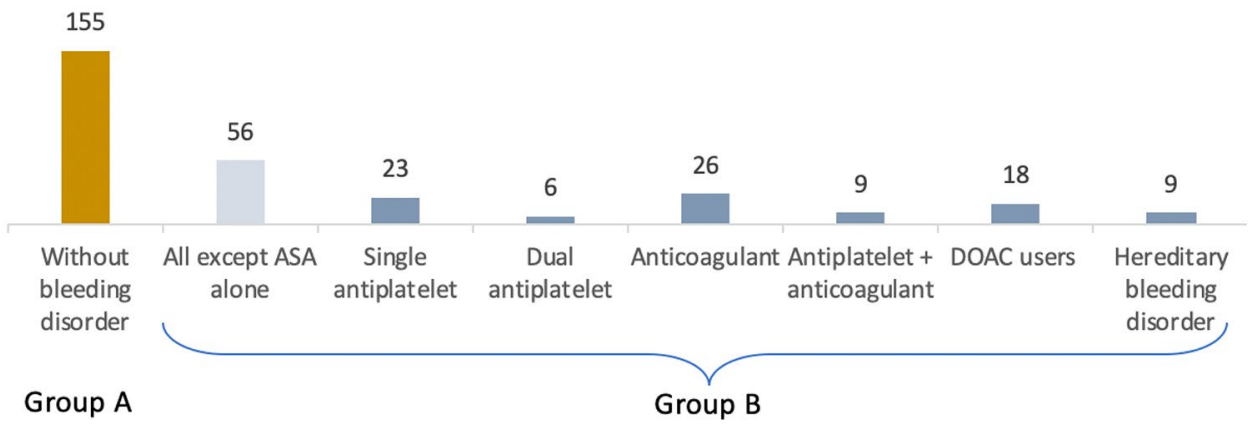

\section{Efficacy evaluation: Intervention period}

The overall therapeutic success rate was $93.4 \%(n=213)$, with no significant differences between groups $(92.9 \% \mathrm{vs}$ $94.5 \%, p=0.646$ ). Treatment was unsuccessful in 11 patients from group A and 4 patients from group B (Table 2).

The average number of sessions per patient was $1.51 \pm 0.74(\min =1, \max =3)$, significantly higher for group B $(1.68 \pm 0.86$ vs $1.43 \pm 0.65, p=0.013)$.

The average volume of polidocanol injected was $22.6 \pm 10.9 \mathrm{~mL}$ (group A: $22.5 \pm 10.5 \mathrm{~mL} v s$ group B: $22.9 \pm 11.7 \mathrm{~mL}$; min. $8 \mathrm{~mL}$, max. $60 \mathrm{~mL}$ ), without significant differences between the two groups $(\mathrm{p}=0.763)$.

\section{Safety evaluation: type and rate of complications}

Complications (Table 3) occurred in $11.4 \%(\mathrm{n}=25)$ of the patients (group A: $12.3 \%$ vs group B: $9.6 \%, p=0.554$ ). Most were mild (96.2\%): pain/discomfort $(n=14)$; minor bleeding $(n=10)$ and dyschezia $(n=1)$. Severe complications occurred in 1 patient group B (rectal bleeding requiring blood transfusion).

Bleeding complications were reported in $4.8 \%(n=11)$ of the participants with no significant differences between the two groups (group A: $4.5 \%, n=7$ vs group B: $5.5 \%, n=4$; $p=0.751)$.

None of the baseline characteristics was a significant predictor for the occurrence of complications (Table 4).

In subgroup analysis, we found no significant differences in rate of complications from PFS between group B subgroups (Table 5).

\section{Efficacy evaluation: Follow-up period}

Two hundred and thirteen patients were included in the follow-up period (group A $n=144$; Group B $n=69$ ); $82.5 \%$ and $80.9 \%$ patients from groups $\mathrm{A}$ and $\mathrm{B}$, respectively, showed no recurrence at 1-year of follow-up. Recurrence rates presented no significant differences between groups at any
Table 4 Hazard ratios for the risk of complications

\begin{tabular}{llll}
\hline & OR & $(95 \% \mathrm{CI})$ & $P$ \\
\hline Age & 1.002 & $(0.972,1.032)$ & 0.919 \\
BMI & 0.892 & $(0.793,1.004)$ & 0.057 \\
Baseline Goligher grade & & & \\
$\quad$ II & 0.376 & $(0.112,1.264)$ & 0.114 \\
III & 0.419 & $(0.106,1.657)$ & 0.215 \\
Baseline hemorrhoidal & & & \\
$\quad$ disease bleeding grade & & & \\
2 & 0.572 & $(0.172,1.900)$ & 0.361 \\
3 & 0.810 & $(0.116,5.673)$ & 0.832 \\
Baseline Sodergren hemor- & 1.109 & $(0.946,1.301)$ & 0.202 \\
$\quad$ rhoidal symptom severity & & & \\
$\quad$ score & & & 0.908 \\
Group (B) & 0.928 & $(0.263,3.273)$ & \\
\hline
\end{tabular}

$O R$ odds ratio, $C I$ confidence interval, $B M I$ body mass index

Table 5 Safety outcomes (group B subgroups)

\begin{tabular}{llll}
\hline & Total—n & $\begin{array}{l}\text { Complica- } \\
\text { tions— } \\
(\%)\end{array}$ & $p$ \\
\hline Group A (without BD) & 155 & $19(12.3)$ & \\
Group B (All except ASA alone) & 56 & $6(10.7)$ & 0.533 \\
Group B (Anticoagulant only) & 26 & $4(15.4)$ & 0.211 \\
Group B (Antiplatelet single) & 23 & $1(4.3)$ & 0.302 \\
Group B (Anticoagulant + antiplate- & 9 & $1(11.1)$ & 0.868 \\
$\quad$ let) & & & \\
Group B (Dual antiplatelet) & 6 & $0(0.0)$ & 0.405 \\
Group B (DOAC users) & 18 & $3(16.7)$ & 0.240 \\
Group B (Hereditary BD only) & 9 & $1(11.1)$ & 0.868 \\
\hline
\end{tabular}

$A S A$ aminosalicylic acid, $D O A C$ direct oral anticoagulants, $B D$ bleeding disorder

Tests used to compare variables between groups: Chi-square test

follow-up time point (Table 6; Fig. 5). Also, the mean time for recurrence at 12 months was not significantly different between the groups (group A: $11.7 \pm 0.10$ months $v s$ group 
Table 6 Efficacy outcomes (disease recurrence)

\begin{tabular}{|c|c|c|c|c|}
\hline & All $(n=213)$ & Group A $(n=144)$ & Group B $(n=69)$ & $p$ value \\
\hline \multicolumn{4}{|l|}{ Recurrence at 3 months } & 0.488 \\
\hline No: $n(\%)$ & $212(99.5)$ & $143(99.3)$ & $69(100.0)$ & \\
\hline Yes: $n(\%)$ & $1(0.5)$ & $1(0.7)$ & $0(0.0)$ & \\
\hline \multirow[t]{2}{*}{ Deceased: $n(\%)$} & $0(0.0)$ & $0(0.0)$ & $0(0.0)$ & \\
\hline & $(n=212)$ & $(n=143)$ & $(n=69)$ & \\
\hline \multicolumn{4}{|l|}{ Recurrence at 6 months } & 0.366 \\
\hline No: $n(\%)$ & $207(99.5)$ & $140(97.9)$ & $67(97.1)$ & \\
\hline Yes: $n(\%)$ & $4(1.9)$ & $3(2.1)$ & $1(1.4)$ & \\
\hline \multirow[t]{2}{*}{ Deceased: $n(\%)$} & $1(0.5)$ & $0(0.0)$ & $1(1.4)$ & \\
\hline & $(n=207)$ & $(n=140)$ & $(n=67)$ & \\
\hline \multicolumn{4}{|l|}{ Recurrence at 9 months } & 0.448 \\
\hline No: $n(\%)$ & $191(92.3)$ & $130(92.9)$ & $61(91.0)$ & \\
\hline Yes: $n(\%)$ & $15(7.2)$ & $9(6.4)$ & $6(9.0)$ & \\
\hline \multirow[t]{2}{*}{ Deceased: $n(\%)$} & $1(0.5)$ & $1(0.7)$ & $0(0.0)$ & \\
\hline & $(n=191)$ & $(n=130)$ & $(n=61)$ & \\
\hline Recurrence at 12 months & & & & 0.894 \\
\hline No: $n(\%)$ & $173(90.6)$ & $118(90.8)$ & $55(90.2)$ & \\
\hline Yes: $n(\%)$ & $18(9.4)$ & $12(9.2)$ & $6(9.8)$ & \\
\hline Deceased: $n(\%)$ & $0(0.0)$ & $0(0.0)$ & $0(0.0)$ & \\
\hline
\end{tabular}

Tests used to compare variables between groups: Chi-square test

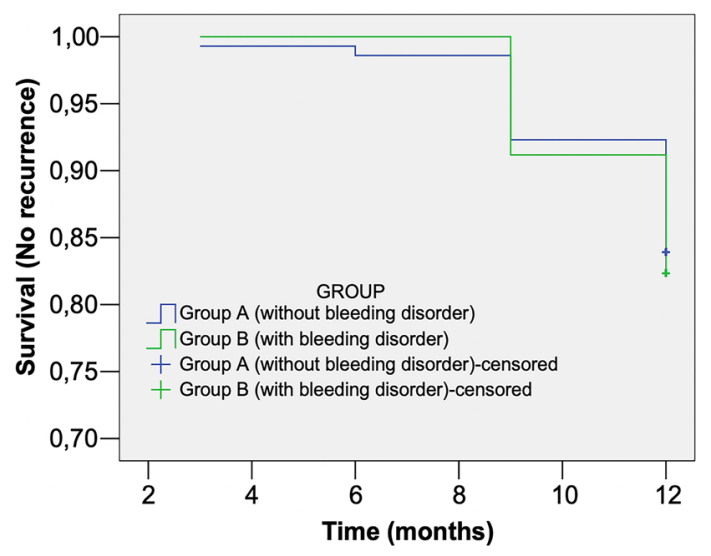

Fig. 5 Recurrence Probability (Cox regression)

Table 7 Mean time for recurrence

\begin{tabular}{llll}
\hline $\begin{array}{l}\text { Mean time for recur- } \\
\text { rence (months) }\end{array}$ & Mean \pm SE & $(95 \% \mathrm{CI})$ & $p$ \\
\hline Group A & $11.71 \pm 0.10$ & $(11.52,11.90)$ & 0.786 \\
Group B & $11.74 \pm 0.11$ & $(11.52,11.95)$ & \\
\hline
\end{tabular}

$S E$ standard error, $C I$ confidence interval

Tests used to compare variables between groups: Log Rank (Mantel Cox) tes
Table 8 Hazard Ratios for the risk of recurrence

\begin{tabular}{llll}
\hline & OR & $(95 \% \mathrm{CI})$ & $p$ \\
\hline Age & 1.023 & $(0.996,1.050)$ & 0.094 \\
BMI & 0.994 & $(0.916,1.077)$ & 0.875 \\
Baseline Goligher grade & & & 0.890 \\
$\quad$ II & 0.841 & $(0.273,2.591)$ & 0.763 \\
$\quad$ III & 0.737 & $(0.208,2.615)$ & 0.636 \\
Baseline hemorrhoidal & & & 0.311 \\
$\quad$ disease bleeding grade & & & \\
$\quad 2$ & 1.539 & $(0.471,5.025)$ & 0.475 \\
$\quad 3$ & 3.194 & $(0.661,15.428)$ & 0.148 \\
Baseline Sodergren hemor- & 1.176 & $(1.045,1.323)$ & $\mathbf{0 . 0 0 7}$ \\
$\quad$ rhoidal symptom severity & & & \\
$\quad$ score & & & 0.065 \\
Group (B) & 0.394 & $(0.147,1.059)$ & \\
\hline
\end{tabular}

$O R$ odds ratio, $C I$ confidence interval, $B M I$ body mass index

B: $11.7 \pm 0.11$ months, $p=0.786$ ) (Table 7). The probability of recurrence was higher for patients with higher baseline SHSS scores $(p=0.007)$. No other characteristics were predictors of recurrence (Table 8).

Two patients, one in each group, died of unrelated causes (respiratory/pulmonary infections), at 6 and 9-month follow-up. 


\section{Discussion}

The aim of our study was to prospectively evaluate the efficacy and safety of PFS in the treatment of symptomatic internal HD grades I to III in patients with a congenital or acquired bleeding disorder (group B), compared to patients without such disorders (group A). To the best of our knowledge, this is the first study to specifically evaluate clinical outcomes in this challenging population, known for having higher bleeding risk related to HD interventions. This prospective, multicentre, cohort study demonstrated that PFS was effective and safe in both groups of patients.

The mean age in our cohort was significantly higher for patients with $\mathrm{BD}$ which can be explained by the fact that older patients are more prone to cardiovascular comorbidities and, as such, need antithrombotic therapy more often. Also, at baseline, the patients with BD had more symptomatic HD with more severe bleeding grade.

We found a significant decrease in HDBG and SHSS scores after the PFS, in both groups of patients. Therapeutic success was reported in $94.5 \%$ and $92.9 \%$ of the patients with and without BD, respectively, without significant differences between the groups. These results are similar to those in the pioneer study of Moser et al. [22] that reported a success rate (assessed by the HDBG) of $88 \%$ and $98 \%$ after the first and the second PFS session, respectively. Our success rate is higher than that reported by Lobascio et al. [28] and our group [23] in a randomized controlled trial comparing PFS with RBL in the treatment of HD grades I-III. Also, Fernandes et al. [21] in a large cohort of patients with HD grades I-IV (including 210 patients under antithrombotic therapy), documented a $98 \%$ decrease in self-reported bleeding and reduction of prolapse in $86 \%$ (out of 1112 reexamined patients) with PFS, concluding that it was effective and safe even in patients on antithrombotic therapy. [15, 21] In a short-term report of PFS used as a bridge treatment in HD grades III-IV during the COVID-19 pandemic [29], all the patients had resolution of bleeding without complications while awaiting surgery. PFS treatment was considered effective, safe, repeatable, and associated with good patient satisfaction. The efficacy of PFS derives from its mechanism of action, which induces a local inflammatory reaction that anchors the hemorrhoidal tissue, leads to obliteration of the vascular bed and consequent fibrosis and tissue shrinkage $[27,28]$. This might explain the clinical benefit as regards the major symptoms of hemorrhoidal disease, including bleeding, pain, prolapse, and relief of soiling and pruritus, due to reduction of vascular congestion.

Our number of PFS treatment sessions per patient was significantly higher for the group with BD which may be due to the higher baseline severity of HD in this group of patients. The number of therapy sessions in the group of patients without $\mathrm{BD}$ is in line with the previously reported by Moser et al. [22] and us [23]. The average polidocanol dose was similar to previous studies [23] and between the groups.

Concerning the safety of PFS treatment, our overall complications rate was similar to previous data published by our group [23], with pain being the most frequent post-procedure complication. However, the definition of pain, including its intensity and duration, varied in previous studies precluding an accurate comparison. Moser et al. [22] described the higher pain rates since they considered very short duration pain (resolving in less than $15 \mathrm{~min}$ ). In that study $97 \%$ of the patients remained pain free between PFS sessions.

We did not find significant differences in the rate or type (mild or severe) of complications between patients with and without $\mathrm{BD}$, and none of the baseline characteristics was a significant predictor for the occurrence of complications. Although none of the group B subgroups had a significantly higher incidence of complications, we noted a higher rate of complications in anticoagulated patients, particularly with DOACs. We should consider a possible small sample size bias that could attenuate potential significant differences.

There are reports of serious complications of HD sclerotherapy such as acute prostatitis [22], major bleeding, urinary retention and sepsis requiring surgery [21]. However, the incidence of major complications appears to be much more common with RBL [18]. The only severe complication in our cohort was bleeding requiring blood transfusion in a patient with $\mathrm{BD}$ (subgroup of anticoagulant + antiplatelet therapy).

Bleeding has been described as the most common complication of HD treatments. RBL is associated with bleeding rates ranging from $2.1 \%$ to $7 \%$ including minor and significant bleeding requiring medical evaluation or transfusion support [20]. There is also an increased risk of late (10-14 days after RBL) and potential life-threatening bleeding for patients on antithrombotic therapy [18]. The standard recommendation for minimizing bleeding risk is to withhold antithrombotic therapy for 7-10 days prior to, and after, hemorrhoidal procedures like RBL or excisional haemorrhoidectomy [11,32]. Some studies on RBL [31] and surgical transanal hemorrhoidal dearterialization (TDH) [32] described a similar risk of bleeding with different suspension protocols and even under anticoagulation [32], without sufficient evidence, however, to modify current recommendations. Our overall bleeding rate of $4.8 \%$ was slightly lower than the $6 \%$ persistent bleeding described by Lobascio et al. [28]. We found a $5.5 \%$ bleeding rate after PFS for patients with $\mathrm{BD}$, without significant differences comparing to patients without $\mathrm{BD}$, while Fernandes et al. [21] reported 9\% significant bleeding (referring to 22 patients under double antithrombotic therapy), in contrast to $0.05 \%$ bleeding in patients without antithrombotic therapy. In our study, none 
of the patients discontinued antiplatelet or anticoagulation therapy prior to PFS treatment and no thrombotic or cardioembolic complications were reported. PFS treatment may thus provide a safer approach for these patients.

Recurrence rates were comparable in both groups with $82.5 \%$ and $80.9 \%$ (groups A and B, respectively) of the patients who had therapeutic success showing no HD recurrence at 1-year follow-up. Previous data showed similar recurrence rates for PFS [23, 28] and significantly higher ones with other techniques: recurrence of prolapse of up to $34 \%$ with liquid polidocanol [16] and a bleeding recurrence ranging from $10-46 \%$ for RBL [18].

There are several strengths in our study. First, the relevance of assessing clinical outcomes of PFS treatment in patients with HD and inherited or acquired BD. These patients are a vulnerable population, more prone to bleeding complications when undergoing invasive procedures, where HD management is much more challenging. We assessed clinical outcomes using validated severity scores, as an attempt to overcome subjective interpretations concerning efficacy of PFS in HD. Our study protocol was multicentric, which aimed to improve generalizability of data, and included a one-year follow-up period, which allowed for a more accurate evaluation of recurrence.

However, our study has some limitations. The heterogeneity of the antithrombotic therapy and the small sample size of the subgroups within the $\mathrm{BD}$ group precluded a more robust analysis. We did not account for the possible influence of distinct antiplatelet therapy dosage on rate of bleeding. Also, the 12-month follow-up is short considering the chronic and relapsing pathogenesis of HD.

Our results regarding the efficacy and safety of PFS for the treatment of internal HD grades I to III are aligned with other recent data which support the use of PFS as a first line procedure. PFS decreased hemorrhoidal bleeding and symptom severity, and was associated with a low incidence of complications even in patients with $\mathrm{BD}$, with no need to carry out any bleeding prophylaxis or discontinue antithrombotic medications thus avoiding an eventual increase in the thrombotic risk.

\section{Conclusions}

Our results suggest that PFS is just as effective and safe for treatment of $\mathrm{HD}$ in patients with $\mathrm{BD}$ as in those without bleeding dyscrasia. Further larger scale studies are needed to determine whether PFS can become the established standard of care in the treatment of HD in patients with BD, as it may offer these patients a safe and effective office-based treatment, without the need to stop antithrombotic drugs or perform bleeding prophylaxis.
Supplementary Information The online version contains supplementary material available at https://doi.org/10.1007/s10151-022-02600-5.

Acknowledgements The authors acknowledge Mafalda Salgueiro, author of the schematic illustration of polidocanol sclerotherapy technique. We also acknowledge Miguel Reis Ferreira who provided critical review of the manuscript.

Author contributions All authors contributed to the study conception and design. Material preparation, data collection and analysis were performed by Paulo Salgueiro, Andreia Rei and Mónica Garrido. The first draft of the manuscript was written by Paulo Salgueiro and all authors commented on previous versions of the manuscript. All authors read and approved the final manuscript.

Funding There is no funding to declare.

Availability of data and material (data transparency) The data that support the findings of this study are available on request from the corresponding author.

Code availability Not applicable.

\section{Declarations}

Conflict of interest The authors declare that they have no conflicts of interest.

Ethics approval (include appropriate approvals or waivers) The study was approved by the Ethics Committee of the intervening institutions (243-18 (213-DEFI/212-CES)).

Consent to participate All participants provided written informed consent to participate in the study, as well as for the publication.

Consent for publication All authors had access to the study data and approved the final manuscript.

\section{References}

1. Salgueiro P, Caetano AC, Oliveira AM, Rosa B, MascarenhasSaraiva M, Ministro P et al (2020) Portuguese society of gastroenterology consensus on the diagnosis and management of Hemorrhoidal disease. GE Port J Gastroenterol 27(2):90-102. https:// doi.org/10.1159/000502260

2. Johanson JF, Sonnenberg A (1990) The prevalence of hemorrhoids and chronic constipation. An epidemiologic study. Gastroenterology 98(2):380-386. https://doi.org/10.1016/0016-5085(90) 90828-o

3. Riss S, Weiser FA, Schwameis K, Riss T, Mittlbock M, Steiner $\mathrm{G}$ et al (2012) The prevalence of hemorrhoids in adults. Int J Colorectal Dis 27(2):215-220. https://doi.org/10.1007/ s00384-011-1316-3

4. Lohsiriwat V (2012) Hemorrhoids: from basic pathophysiology to clinical management. World J Gastroenterol 18(17):2009-2017. https://doi.org/10.3748/wjg.v18.i17.2009

5. Sun Z, Migaly J (2016) Review of Hemorrhoid disease: presentation and management. Clin Colon Rectal Surg 29(1):22-29. https://doi.org/10.1055/s-0035-1568144 
6. van Tol RR, Kimman ML, Melenhorst J, Stassen LPS, Dirksen CD, Breukink SO et al (2019) European society of coloproctology core outcome set for haemorrhoidal disease: an international delphi study among healthcare professionals. Colorectal Dis 21(5):570-580. https://doi.org/10.1111/codi.14553

7. Qureshi WA (2018) Office management of hemorrhoids. Am J Gastroenterol 113(6):795-798. https://doi.org/10.1038/ s41395-018-0020-0

8. Rorvik HD, Styr K, Ilum L, McKinstry GL, Dragesund T, Campos AH et al (2019) Hemorrhoidal disease symptom score and short health ScaleHD: New Tools to Evaluate Symptoms and Health-Related Quality of Life in Hemorrhoidal Disease. Dis Colon Rectum 62(3):333-342. https://doi.org/10.1097/DCR. 0000000000001234

9. Pucher PH, Qurashi M, Howell AM, Faiz O, Ziprin P, Darzi A et al (2015) Development and validation of a symptom-based severity score for haemorrhoidal disease: the Sodergren score. Colorectal Dis 17(7):612-618. https://doi.org/10.1111/codi. 12903

10. Sha HL, Roslani AC, Poh KS (2020) Evaluating the ability of the Sodergren score to guide the management of internal haemorrhoidal disease. Colorectal Dis 22(10):1379-1387. https://doi.org/10. $1111 /$ codi. 15091

11. Gallo G, Martellucci J, Sturiale A, Clerico G, Milito G, Marino F et al (2020) Consensus statement of the Italian society of colorectal surgery (SICCR): management and treatment of hemorrhoidal disease. Tech Coloproctol 24(2):145-164. https://doi.org/10.1007/ s10151-020-02149-1

12. Goligher J DH, Nixon H (1984) Surgery of the anus, rectum and colon. Fifth edition ed. Tindall B, editor. London

13. Cataldo P, Ellis CN, Gregorcyk S, Hyman N, Buie WD, Church $\mathrm{J}$ et al (2005) Practice parameters for the management of hemorrhoids (revised). Dis Colon Rectum 48(2):189-194. https://doi. org/10.1007/s10350-004-0921-4

14. Jongen J, Kahlke V (2019) Quality indicators in the treatment of hemorrhoids. Chirurg 90(4):264-269. https://doi.org/10.1007/ s00104-018-0787-y

15. Rosa B (2019) Polidocanol foam: a breath of fresh air for the treatment of internal hemorrhoids. GE Port J Gastroenterol 26(3):153154. https://doi.org/10.1159/000493440

16. Cocorullo G, Tutino R, Falco N, Licari L, Orlando G, Fontana $\mathrm{T}$, et al (2017) The non-surgical management for hemorrhoidal disease A systematic review. G Chir 38(1):5-14. https://doi.org/ 10.11138/gchir/2017.38.1.005

17. Tutino R, Salamone G, De Marco P, Cocorullo G, Gulotta G (2021) Outpatient treatment of hemorrhoidal disease: the alternative way to treat Hemorrhoidal disease in a simple, safe and effective manner. Rev Recent Clin Trials 16(1):5-9. https://doi. org/10.2174/1574887115666200305150029

18. Albuquerque A (2016) Rubber band ligation of hemorrhoids: a guide for complications. World J Gastrointest Surg 8(9):614-620. https://doi.org/10.4240/wjgs.v8.i9.614

19. Poen AC, Felt-Bersma RJ, Cuesta MA, Deville W, Meuwissen SG (2000) A randomized controlled trial of rubber band ligation versus infra-red coagulation in the treatment of internal haemorrhoids. Eur J Gastroenterol Hepatol 12(5):535-539. https://doi. org/10.1097/00042737-200012050-00010

20. Iyer VS, Shrier I, Gordon PH (2004) Long-term outcome of rubber band ligation for symptomatic primary and recurrent internal hemorrhoids. Dis Colon Rectum 47(8):1364-1370. https://doi.org/ 10.1007/s10350-004-0591-2

21. Fernandes V, Fonseca J (2019) Polidocanol foam injected at high doses with intravenous needle: The (Almost) perfect treatment of symptomatic internal hemorrhoids. GE Port J Gastroenterol 26(3):169-175. https://doi.org/10.1159/000492202
22. Moser KH, Mosch C, Walgenbach M, Bussen DG, Kirsch J, Joos AK et al (2013) Efficacy and safety of sclerotherapy with polidocanol foam in comparison with fluid sclerosant in the treatment of first-grade haemorrhoidal disease: a randomised, controlled, single-blind, multicentre trial. Int J Colorectal Dis 28(10):14391447. https://doi.org/10.1007/s00384-013-1729-2

23. Salgueiro P, Garrido M, Gaio R, Ruben M, Pedroto I, CastroPoças F (2021) Polidocanol foam sclerotherapy versus rubber band ligation in hemorrhoidal disease Grades I, II and III: randomized trial. Dis Colon Rectum. https://doi.org/10.1097/DCR. 0000000000002117

24. Makanjuola A, Balogun OS, Osinowo AO, Adesanya AA, da Rocha JT (2020) Comparison of rubber band ligation with $3 \%$ polidocanol injection sclerotherapy for the treatment of internal haemorrhoids at a Nigerian tertiary hospital. Niger Postgrad Med J 27(4):311-316. https://doi.org/10.4103/npmj.npmj_232_20

25. Nastasa V, Samaras K, Ampatzidis C, Karapantsios TD, Trelles MA, Moreno-Moraga J et al (2015) Properties of polidocanol foam in view of its use in sclerotherapy. Int J Pharm 478(2):588 596. https://doi.org/10.1016/j.ijpharm.2014.11.056

26. Gallo G, Ronconi M, Trompetto M (2021) Sclerotherapy with 3\% polidocanol foam: revolutionizing outpatient treatment in patients with haemorrhoidal disease. Updates Surg 73(5):2029-2030. https://doi.org/10.1007/s13304-021-01008-4

27. Zheng X, Wei Q, Zhang H (2018) Novel developments in polidocanol sclerotherapy: a review. J Biosci Med. 6:31-41. https://doi. org/10.4236/jbm.2018.68003

28. Lobascio P, Laforgia R, Novelli E, Perrone F, Di Salvo M, Pezzolla A et al (2021) Short-term results of sclerotherapy with $3 \%$ polidocanol foam for symptomatic second- and third-degree hemorrhoidal disease. J Invest Surg 34(10):1059-1065. https://doi.org/ 10.1080/08941939.2020.1745964

29. Lisi G, Campanelli M, Grande S, Milito G, Grande M (2021) Sclerotherapy with $3 \%$ polidocanol foam for third- and fourthdegree hemorrhoids as "bridge treatment" during the COVID-19 pandemic in Italy. Int J Colorectal Dis 36(6):1321-1322. https:// doi.org/10.1007/s00384-021-03848-3

30. Ronconi MCS, Shieppati M (2019) EndoTHeF: Endoluminal Treatment of Hemorrhoids with Foam. Ann Colorectal Res. 6(4):e86297

31. Nelson RS, Ewing BM, Ternent C, Shashidharan M, Blatchford GJ, Thorson AG (2008) Risk of late bleeding following hemorrhoidal banding in patients on antithrombotic prophylaxis. Am J Surg 196(6):994-999. https://doi.org/10.1016/j.amjsurg.2008.07. 036

32. Atallah S, Maharaja GK, Martin-Perez B, Burke JP, Albert MR, Larach SW (2016) Transanal hemorrhoidal dearterialization (THD): a safe procedure for the anticoagulated patient? Tech Coloproctol 20(7):461-466. https://doi.org/10.1007/ s10151-016-1481-z

33. Pengo V, Pegoraro C, Cucchini U, Iliceto S (2006) Worldwide management of oral anticoagulant therapy: the ISAM study. J Thromb Thrombolysis 21(1):73-77. https://doi.org/10.1007/ s11239-006-5580-y

34. Swan D, Loughran N, Makris M, Thachil J (2020) Management of bleeding and procedures in patients on antiplatelet therapy. Blood Rev 39:100619. https://doi.org/10.1016/j.blre.2019.100619

35. Albrecht H, Maass LS, Hagel AF, Neurath MF, Konturek PC, Raithel M (2019) Anticoagulant-related gastrointestinal bleeding a real-life data analysis on bleeding profiles, frequency and etiology of patients receiving direct oral anticoagulants versus vitamin K antagonists. J Physiol Pharmacol https://doi.org/10.26402/jpp. 2019.6.11

36. Yusuf S, Islam S, Chow CK, Rangarajan S, Dagenais G, Diaz R et al (2011) Use of secondary prevention drugs for cardiovascular disease in the community in high-income, middle-income, and 
low-income countries (the PURE Study): a prospective epidemiological survey. Lancet 378(9798):1231-1243. https://doi.org/10. 1016/S0140-6736(11)61215-4

37. Pannach S, Goetze J, Marten S, Schreier T, Tittl L, Beyer-Westendorf J (2017) Management and outcome of gastrointestinal bleeding in patients taking oral anticoagulants or antiplatelet drugs. J Gastroenterol 52(12):1211-1220. https://doi.org/10.1007/ s00535-017-1320-7

38. Miller CS, Dorreen A, Martel M, Huynh T, Barkun AN (2017) Risk of Gastrointestinal Bleeding in Patients Taking Non-Vitamin K Antagonist Oral Anticoagulants: A Systematic Review and Meta-analysis. Clin Gastroenterol Hepatol 15(11):1674-1683e3. https://doi.org/10.1016/j.cgh.2017.04.031

39. Sorensen R, Hansen ML, Abildstrom SZ, Hvelplund A, Andersson C, Jorgensen C et al (2009) Risk of bleeding in patients with acute myocardial infarction treated with different combinations of aspirin, clopidogrel, and vitamin $\mathrm{K}$ antagonists in Denmark: a retrospective analysis of nationwide registry data. Lancet 374(9706):1967-1974. https://doi.org/10.1016/S0140-6736(09) 61751-7

40. Rothberg MB, Celestin C, Fiore LD, Lawler E, Cook JR (2005) Warfarin plus aspirin after myocardial infarction or the acute coronary syndrome: meta-analysis with estimates of risk and benefit. Ann Intern Med 143(4):241-250. https://doi.org/10.7326/00034819-143-4-200508160-00005

41. Lanas A, Carrera-Lasfuentes P, Arguedas Y, Garcia S, Bujanda L, Calvet $X$ et al (2015) Risk of upper and lower gastrointestinal bleeding in patients taking nonsteroidal anti-inflammatory drugs, antiplatelet agents, or anticoagulants. Clin Gastroenterol Hepatol 13(5):906-12 e2. https://doi.org/10.1016/j.cgh.2014.11.007

42. Sherwood MW, Nessel CC, Hellkamp AS, Mahaffey KW, Piccini JP, Suh EY et al (2015) Gastrointestinal bleeding in patients with atrial fibrillation treated with rivaroxaban or warfarin: ROCKET AF trial. J Am Coll Cardiol 66(21):2271-2281. https://doi.org/10. 1016/j.jacc.2015.09.024

43. Tsagianni A, Comer DM, Yabes JG, Ragni MV (2019) Von Willebrand disease and gastrointestinal bleeding: A national inpatient sample study. Thromb Res 178:119-123. https://doi.org/10.1016/j. thromres.2019.04.017

44. Tomaszewski M, Bienz M, Kherad O, Restellini S, Lafleche T, Barkun A et al (2019) Low endoscopy bleeding risk in patients with congenital bleeding disorders. Haemophilia 25(2):289-295. https://doi.org/10.1111/hae.13691

45. Ingerslev J, Hvid I (2006) Surgery in haemophilia. The general view: patient selection, timing, and preoperative assessment. Semin Hematol 43(1 Suppl 1):S3-S26. https://doi.org/10.1053/j. seminhematol.2005.11.024

46. Tessari L, Cavezzi A, Frullini A (2001) Preliminary experience with a new sclerosing foam in the treatment of varicose veins. Dermatol Surg 27(1):58-60

47. Rodeghiero F, Tosetto A, Abshire T, Arnold DM, Coller B, James $P$ et al (2010) ISTH/SSC bleeding assessment tool: a standardized questionnaire and a proposal for a new bleeding score for inherited bleeding disorders. J Thromb Haemost 8(9):2063-2065. https:// doi.org/10.1111/j.1538-7836.2010.03975.x

Publisher's Note Springer Nature remains neutral with regard to jurisdictional claims in published maps and institutional affiliations. 